\title{
Da implicância à implicação: possibilidades de ocupação da posição de professor no ensino de escrita
}

\section{From niggling to implication: possibilities of occupying the teacher's position in teaching writing}

https://doi.org/10.34112/2317-0972a2017v35n69p73-86

\section{Carla Nunes Vieira Tavares ${ }^{1}$}

Resumo: A partir da análise de um relato de experiência docente, este artigo objetiva discutir saídas para o discurso de vitimização que caracteriza a ocupação da posição de professor de línguas, em especial no que diz respeito à escrita. Com base na mobilização de algumas noções da psicanálise lacaniana, a formação e o processo de ensino-aprendizagem são abordados, de modo a reivindicar que a transmissão do saber implique o investimento subjetivo, sendo impulsionada pela transferência. As considerações da análise do relato apontam que uma maior implicação na posição de professor estaria na dependência de uma relação criativa entre sujeito e saber, possibilitando ao docente abrir mão de um discurso de vitimização para assumir uma postura inventiva e responsável sobre a posição de professor. PALAVRAS ChAVE: Ensino-aprendizagem de línguas; formação de professores; escrita.

ABSTRACT: Through analyzing a teaching experience report, this article aims to discuss solutions to the victimization discourse which characterizes the discursive position of language teachers, especially in regards to the teaching of writing. Based on certain notions of the Lacanian psychoanalysis, teacher education and the language teaching-learning process are addressed, in order to support the idea that the transmission of knowledge depends on subjective investment, being prompted by the transfer process. In the report's analysis it is

1. Universidade Federal de Uberlândia, Uberlândia, MG, Brasil. 
Da implicância à implicação: possibilidades de ocupação da posição de...

pointed out that a higher involvement in taking up the teacher position would be closely related to a creative relationship between subject and knowledge, allowing the educator to let go of a discourse of victimization in order to assume an inventive and responsible posture about the position of the teacher.

KEYWORDS: Language teaching-learning; teacher education; writing.

O ensino-aprendizagem de línguas tem sido recorrentemente discursivizado em torno da pregnância da falta: falta estrutura, política, compromisso, conhecimento, engajamento, criticidade, saber, dentre outras ${ }^{2}$. Tem sido comum na mídia a divulgação de resultados insatisfatórios das provas de redação dos exames seletivos para o ingresso no ensino superior ou dos concursos para cargos públicos que aludem a essas tantas "faltas". Dentre os motivos assinalados para tal desempenho, encontram-se discursividades ${ }^{3}$ que, por um lado, recriminam o aluno pelo seu desinteresse pelas práticas letradas e/ou por sua pretensa incapacidade de desenvolver uma prática de escrita crítica que ultrapasse a esfera da reprodução de ideias. Por outro lado, o professor também é criticado, sendo-lhe imputada a responsabilidade por não conseguir levar a termo uma relação entre teoria e prática que capacite os alunos a tomarem uma posição na escrita e, assim, darem mostras de uma inscrição na cultura letrada. Há, ainda, discursividades que atribuem à formação de professores as falhas do ensino-aprendizagem de línguas, pois ela não lhes propiciaria suficientes instâncias significativas para promover uma relação teoria-prática-pesquisa.

Paradoxalmente, no entanto, tantas faltas podem remeter ao processo de "entodamento", conforme o designa Lebrun (2008), o qual constitui uma das características da contemporaneidade. Com o termo, o psicanalista chama a atenção para a tendência de uma lógica voltada para relações de reciprocidade, para uma aposta na comunicação, na resignação, na igualdade, na imagem. No que concerne à educação, a ilusão de "entodamento" se reflete na busca pelo processo pleno, democrático, sem falhas. O laço social calcado no "entodamento" ignora a negatividade e produz objetos de consumo. Aquilo que se apresenta como "falta" remete não ao vazio no

2. Baghin-Spinelli (2002) analisou, em sua tese de doutorado, o discurso da falta no contexto da formação de professores e no dizer de professores em serviço.

3. Em uma perspectiva discursiva afetada por uma filiação pós-estruturalista e por uma teoria não subjetivista da subjetividade, o termo "discursividade" se refere ao conjunto de dizeres sobre um determinado objeto do discurso, afetados pela exterioridade constitutiva da linguagem, a saber, o sócio, o histórico, o ideológico e a subjetividade. As discursividades têm a potencialidade de provocar deslocamentos nos efeitos de sentido em uma esfera enunciativa relacionada a um campo de saberes (SANTOS, 2007). 
qual se funda toda e qualquer possibilidade do exercício da subjetividade, mas à viabilidade de preenchê-lo por completo. O "entodamento" seria a resultante de uma outra lógica na constituição do laço social, que se institui no escamoteamento do registro do real, da alteridade e da negatividade, e tem como produto um objeto positivado, debilmente simbolizado, circunscrito à esfera do consumo imediato.

Assim, as discursividades da falta indiciam a crença na possibilidade de uma correspondência entre aquilo que uma formação se propõe a ensinar e aquilo que o aluno vai aprender, entre o que o professor ensina e o que o aluno aprende e entre as demandas do aluno e as expectativas do professor. Em outras palavras, a formação aparece representada como dotada de certa onipotência, porque ela se baseia na possibilidade de haver soluções que preencham a falta, de promover uma autonomia que instrumentalize o professor, capacitando-o a refletir e buscar melhores alternativas. A formação, então, por mais que se proponha contínua, reflexiva e crítica, palavras quase de ordem nos contextos de cursos de licenciatura ou docência, está direcionada para o alcance de um ideal positivado.

Todavia, para acreditar em tal relação de reciprocidade, é preciso mesmo exercer muita fé. A fratura que se instaura em tal idealização, mediante a contingência de uma formação e de um processo de ensino-aprendizagem, gera uma angústia paralisante, na medida em que a falta é justamente o que parece faltar. Uma saída para expressar essa angústia se configura no discurso da implicância, que nada mais acrescenta ao cenário senão reforçar o imaginário de que não há muito mais a fazer. No que concerne ao escopo deste trabalho, a saber, a formação de professores de línguas, parece-me que duas alternativas se configuram como as mais procuradas. Por um lado, a formação se circunscreve a um caráter tecnicista, reduzindo-a ao ensino de técnicas e metodologias de ensino que capacitariam os professores a aplicá-las. Por outro, a aposta na possibilidade de que a pretensa autonomia promovida pela reflexão crítica encorajada durante a formação se encarregue de capacitar o professor a buscar o conhecimento que a situação de ensino demandar. Assim, o processo corre o risco de resumir-se ao tecnicismo, ao pragmatismo e ao esvaziamento do saber.

Este artigo, entretanto, defende que a apropriação da posição de professor requer de alguém estar comprometido com a mestria e constituído do desejo de transmissão, o que ultrapassa em muito a técnica e convoca um saber. Concordo, assim, com Stolzmann e Rickes (1999, p. 49), quando ponderam que "[O] mestre ensina porque é seu dever, porque é sua missão, porque transmitir é seu sintoma, é o que o funda como sujeito". Não se trata, porém, de uma relação de transposição de conhecimentos 
Da implicância à implicação: possibilidades de ocupação da posiçãa de...

de um para o outro, a qual também se apresenta como um projeto completável. Antes, se refere à demanda de saber, em jogo em uma relação pedagógica que requer fazer do ensino uma permanente possibilidade de invenção. Este tipo de ensino se baseia na relação transferencial que pode (ou não) ser instaurada entre dois sujeitos. Consequentemente, enseja a demoção de um sujeito de seus pontos de ancoragem a um conhecimento particular para outros portos que o levem a apre(e)nder algo do conhecimento universal. Assim, um ensino tem a chance de superar a mera reprodução e ensejar a instauração de um laço social em que o sujeito esteja implicado e o resultado do trabalho de implicação seja a produção de algo novo (LACAN, 1969-70/1992).

Portanto, este texto, pretende analisar a subjetividade em jogo na prática do professor de línguas, considerando indissociável a relação entre teoria e prática, a partir de uma perspectiva teórica comprometida com a psicanálise freudo-lacaniana.

A transmissão de um saber se articula em uma dupla demanda. Demanda daquele que não sabe, direcionada a quem se supõe o saber; e demanda daquele em quem se supõe o saber, endereçada a quem o demanda, a fim de ensejar que dele venha a se apropriar. Essa dupla articulação prevê um aquém e um além da deman$\mathrm{da}$, que institui desdobramentos relevantes na relação que se estabelece com o saber no processo de formação.

$\mathrm{O}$ aquém da demanda se refere à injunção de que alguém suporte o lugar de suposto saber. A consideração de que o sujeito se constitui e é constituído no e por meio do Outro imputa a essa instância tanto o lugar dos significantes que compõem um ensino e uma aprendizagem, como o campo da linguagem por meio da qual o processo poderá se dar. Mas é preciso que alguém venha fazer semblante do Outro para que o saber que aí pode ser elaborado seja transmitido. Como não há semblante capaz de encarnar o Outro, e a linguagem não é suficiente para representar o mundo, o saber que confiamos a alguém não passa de suposto e precisa manter esse status, a fim de suscitar o desejo que sustenta uma formação. $O$ aquém da demanda sinaliza, ainda, que o lugar de sujeito suposto saber seja ocupado por alguém em quem se reputa um mais saber do que aquele que o demanda. Há uma hierarquia inerente à relação estabelecida entre quem demanda e quem é suposto saber, a qual prevalece, apesar da horizontalidade que caracteriza as relações sujeitudinais na contemporaneidade. Tal hierarquia se sustenta na autoridade engendrada no saber, no enigma desse saber e não no autoritarismo de uma posição de onipotência.

O além da demanda, por sua vez, alude ao saber que sustenta uma filiação. Logo, a transmissão de um saber se "sustenta dos significantes paternos que constituíram 
quem ensina - e quem aprende" (STOLZMANN; RICKES, 1999, p. 49). Porém, a transmissão não pode se ater a um passado. $\mathrm{O}$ saber precisa ser investido subjetivamente como uma herança que propicia às novas gerações o status de humano, de modo a construírem um lugar entre seus pares. No que diz respeito à formação de professores, trata-se da transmissão do desejo de ensinar. Num primeiro momento, ela pode se dar por meio das identificações que instauramos aos nossos primeiros professores. No entanto, se o desejo de transmissão permanecer alienado aos modelos de nossos mestres, a herança permanecerá intacta. $\mathrm{O}$ ensino que se instaura é da ordem de uma reprodução fake. O além da demanda aponta, então, para a segunda milha implícita na transmissão. Em outras palavras, a apropriação de uma herança só se efetua na medida em que seja possível a instauração de identificações ao desejo daquele que a transmite, possibilitando que ela seja investida subjetivamente e resulte em um ensino dotado de estilo próprio. É o estilo que será capaz de sustentar alguém na posição de suposto saber e, assim, articular as demandas do universal da educação com a contingência inesperada da sala de aula, resultando em uma postura inventiva, conforme comenta Lacan (1962-63/2005, p. 190-191) sobre o desejo do professor:

Não é inútil nos apercebermos de que o professor se define como aquele que ensina sobre ensinamentos. Se fosse mais conhecida a verdade de que se trata de algo análogo à colagem, isso permitiria aos professores introduzir aí uma arte mais consumada, da qual a colagem, tal como ganhou sentido através da obra de arte, mostra-nos o caminho. Se eles fizessem sua colagem de maneira menos preocupada com a continuidade, menos comedida, teriam alguma chance de chegar ao mesmo resultado a que visa a colagem, ou seja, evocar a falta que responde por todo o valor da própria obra figurativa, quando ela é bem sucedida, é claro. E assim, por esse caminho, eles conseguiriam atingir o efeito próprio do que é, justamente, um ensino.

É relevante ponderar ainda que o além da demanda se refere à suposição do saber e não à sua garantia. Na possível transferência que se instaura em uma formação, aquele que está sendo formado se dirige ao formador movido pelo desejo de saber. Este não pode aceder ao desejo de seu aluno, mas faz semblante de um saber que faz crer àquele que o demanda que um dia ele será seu (LAJONQUIÈRE, 1997, p. 36). O desejo, porém, só vigora se a falta se mantém e se aquele que porta o semblante se responsabiliza por essa posição. Em uma formação, o formador comparece 
Da implicância à implicação: possibilidades de ocupação da posiçãa de...

com um saber faltoso, que remete o aluno ao saber que está em outro lugar e que precisa ser construído sob os efeitos do desejo.

Desse modo, a responsabilidade por sustentar o lugar de suposto saber depende da assunção de um sujeito à condição de parlêtre. Em outras palavras, somos seres falantes e, como tais, sujeitos ao real, o que nos confronta com a impossibilidade de tudo dizer, de tudo ter, de tudo satisfazer, de tudo saber. De saída, o desdobramento é a instauração de uma postura questionadora quanto à representação de completude do saber, idealizada em uma formação, e a possibilidade de um movimento investigador, motor de uma transmissão significante. Por aprendizagem significante, sinalizo um afastamento de concepções pedagógicas humanistas que atribuem o sucesso do ensino-aprendizagem a um conteúdo que faça sentido para o aluno ou à consideração de um conhecimento prévio, restringindo o processo a um caráter pragmático e utilitarista. Uma transmissão significante não conta necessariamente com o sentido, mas com os efeitos que um saber pode ou não vir a provocar sobre um sujeito, sua relação com o objeto de saber e sua posição subjetiva no mundo.

Ademais, a responsabilidade perante um ensino e um saber compreende o cuidado em relação àqueles que estão em formação. Refiro-me ao princípio "responsabilidade", discutido por Jonas (2006). Trata-se de considerar que, na sociedade tecnológica em que vivemos, as ações humanas têm efeitos sem precedentes sobre os objetos do mundo, ganham proporções e geram consequências inéditas. $\mathrm{O}$ escopo sobre o qual pesa a responsabilização amplia-se do humano para tudo sobre o qual este exerce poder. Considerando, com Foucault (1975/1997, p. 29), que "não há relação de poder sem constituição correlata de um campo de saber, nem saber que não suponha e não constitua ao mesmo tempo relações de poder", a formação de professores constitui um objeto sobre o qual o formador precisa se responsabilizar eticamente.

Primeiramente, portanto, uma formação responsável inclui em seu escopo uma preocupação com a relação que o futuro docente tem com o objeto de saber em jogo na relação pedagógica.

Consequentemente, a formação precisa comprometer-se em colar os cacos fragmentados que resultaram de um processo de desmaterialização do saber na contemporaneidade (ARENDT, 2005). Trata-se de resgatar, em um conjunto de saberes, o objeto de saber em jogo, o saber sobre ensinar e aprender esse objeto, de forma que o conjunto possa constituir uma boa mostra da produção do conhecimento universal do campo de saber. Comprometer-se-á, também, com a apresentação dessa mostra, a fim de possibilitar uma recriação do caminho da construção 
do conhecimento de modo singular e igualmente responsável. Finalmente, mas não unicamente, concordo com Barzotto (2012, p. 31), que prevê que ensinar e aprender estão na dependência de uma disposição "a fazer o percurso em direção ao saber junto com o outro", o que "demanda um refazer, uma disposição para vivenciar o aprendizado de novo, no percurso do aluno".

Tanto o formador como o formando se encontram implicados nesse tipo de formação, calcada em uma relação dialógica, mas não correspondente. Por certo que a angústia aí incidirá, pois tal processo requer dos envolvidos em uma formação uma constante revisitação de sua posição subjetiva frente ao saber. Instaura-se, assim, a necessidade de renunciar à posição narcísica, que prevê a probabilidade de tudo saber, tudo ser e tudo oferecer, objetivando atender às demandas de satisfação do outro. Ao mesmo tempo, será preciso sustentar o lugar de suposto saber para endereçar as demandas daquele que está em formação. Nesse mo(vi)mento, há uma chance de instaurar-se a falta, para que o desejo passe a vigorar na relação com o saber. Novamente, ressalto o aparente paradoxo que reputa justamente à falta uma saída da angústia implicante para uma angústia implicada, na medida em que a falta presentifica a impossibilidade estrutural da completude. Uma angústia implicada é aquela que se vale do desejo como saída para dirigir-se para outros objetos e, assim, promover uma relação criativa com aquilo que, na prática docente, se configura como contingente e, às vezes, toma a forma do impossível.

Diante dessas considerações, analiso uma situação de ensino de língua portuguesa em que foi possível observar uma implicação subjetiva dos envolvidos.

A situação se deu no nono ano do ensino fundamental, em uma escola de aplicação filiada a uma instituição de ensino superior federal. $O$ contexto foi a imperativa retomada das aulas do referido ano, mesmo em meio à greve dos docentes do ensino federal, a fim de possibilitar aos alunos o ingresso no ensino médio em outras instituições de ensino, visto que a escola só oferece o ensino fundamental. A análise do relato de experiência escrito voluntariamente pela professora de Língua Portuguesa da referida escola levou em conta indícios, na materialidade linguística, que remeteriam à tomada de uma posição implicada com a transmissão do saber.

Com a palavra, então, a própria professora, que narrou o que ela chamou de "vivência em sala de aula"4:

4. Por questões de espaço e a fim de perseguir o objetivo da análise, apenas os excertos do relato que interessam a este trabalho estão reproduzidos aqui. Eles foram reproduzidos tais como escritos pela professora. 
Da implicância à implicação: possibilidades de ocupação da posição de...

Como o movimento grevista recebeu fortes e persistentes ataques da sociedade como um todo e, especialmente, da comunidade $[\mathrm{x}],[. .$.$] eu tive a certeza de que a volta com os 9^{o^{s}}$ anos deveria ser planejada no tocante ao movimento grevista, para que eu contribuísse ao esclarecimento do público sobre a situação de hostilidade vivida pelos professores diante das negativas de reivindicações e do descaso do governo federal com a classe e, por conseguinte, com o ensino. A certeza dessa atitude deveu-se, dentre outras causas, pelo acompanhamento de postagens de meus alunos sobre a greve em redes sociais, o que me deixou bastante preocupada e contribuiu para minha mobilização quanto à necessidade de sensibilizá-los para as informações que eram omitidas pela mídia, como um todo.

Nas duas primeiras aulas após o retorno da greve, minha decisão primeira foi escutar os alunos quanto às suas impressões sobre o movimento, todavia, essa escuta deveria ser orientada. [...] Para tanto, resolvi pedir aos discentes que escolhessem uma palavra que representasse $o$ sentimento deles com relação à greve dos professores. Após a escolha, em uma folha de papel, os alunos deveriam escrever as razões para a eleição da palavra; logo, deveriam argumentar sobre sua decisão. Tendo terminado o tempo necessário para a atividade, pedi a eles, um a um, que comentassem sobre a palavra escolhida. O resultado foi uma conversa organizada e sem tumulto sobre o sentimento deles. Claro que para isso delimitamos regras: por exemplo, cada aluno tinha dois minutos para se pronunciar e caso alguém quisesse comentar sobre a fala de um colega, deveria esperar o colega terminar sua fala e, então, teria um minuto para comentar. [...] Em um segundo momento da aula, após a fala dos alunos, resolvi pedir a eles um tempo para escutarem o que eu tinha para falar sobre o movimento, já que eu os tinha escutado. Comecei minha fala, dizendo que a minha intenção, naquele momento, era de contribuir para informar os alunos quanto às causas da greve e quanto à resposta do governo diante da situação, para que, depois, eles pudessem tirar suas próprias conclusões, mas conclusões fundamentadas em informação procedente. Assim foi.

[...] Uma vez esclarecidos sobre as causas do movimento, os discentes se mostraram, em maioria (claro que jamais pensei que conseguisse mobilizar todos e realmente não consegui), revoltados com o governo e o descaso deste com a educação. Ou seja, se antes a revolta era com os professores que não terminavam a greve, a partir da minha fala, a revolta postou-se contra o governo. E foi muito bom vê-los reagindo assim, confesso.

[...]A próxima atividade proposta requereu dos alunos, agora informados sobre a situação, a elaboração de um mapa conceitual sobre a greve. Para tanto, os discentes, que já sabiam o que era e como fazia um mapa conceitual (isso porque já tinham estudado o mapa com o professor de geografia), tiveram de criar um levando em consideração o contexto do movimento grevista e sua sensação, sua posição sujeito responsivo ativo diante da situação. Antes 
de iniciarem, elaborei o meu mapa no quadro expliquei as relações que nele foram construídas. Nem todos os alunos fizeram o mapa conceitual, uns por desinteresse e outros porque, a meu ver, não estavam sentindo-se confortáveis o suficiente para fazê-lo. A minha decisão foi não cobrar as produções. Após a elaboração de cada mapa, os alunos tiveram de, oralmente, explicar as relações constituídas e estabelecidas pelo mapa. Foi um momento maravilhoso, devido à genialidade das relações estabelecidas no mapa; indicação de que, de fato, a escolha por esclarecer os alunos sobre as reivindicações dos professores na greve surtiu efeitos.

[...] Nas aulas geminadas seguintes, os alunos, [...] deveriam escrever um texto argumentativo sobre o movimento grevista - conteúdo esperado para o ano de ensino: argumentação e texto opinativo. [...] Alguns textos, após escritos, passaram por reescritas até sua versão final e foram publicados no site da escola, modo a socializar reflexões por parte, do que a comunidade, em maioria, entedia como "prejudicados". [...] antes de passar à produção do texto escrito, os alunos foram sensibilizados pelo vídeo de Renato Russo cantando "Que país é esse?". Essa música muito colaborou para a fomentação ao tema da greve, mas abrangendo outros setores; o que pretendi foi utilizar a música para que os alunos não somente refletissem sobre a greve, mas estendessem sua reflexão à relação entre o povo, o país e seus governantes: como tem sido estabelecida essa relação ao longo dos anos?

Após essa atividade de produção escrita, a docente deu por finalizada a sequência didática planejada. Discuto, a seguir, alguns pontos que merecem uma análise à luz das considerações feitas até aqui.

O primeiro deles se refere à angústia sobre a qual se pautou a decisão da professora quanto ao que fazer diante de uma situação aparentemente potencializadora de apatia e improdutividade: a retomada obrigatória das aulas em que tanto alunos como professores se encontravam insatisfeitos com a greve. Se, por um lado, a desaprovação da sociedade, resultante de informações desencontradas e parciais, poderia gerar nos alunos a demanda de que o programa simplesmente fosse completado para fins de conclusão do ensino fundamental, por outro os professores encontravam-se acuados diante do panorama da greve e, ainda assim, precisavam retomar as aulas com os nonos anos. A angústia resultante da "preocupaçãos" da professora antecedeu a "certeza" de uma decisão: era preciso fazer algo que não se reduzisse a perpetuar um fazer de conta que se ensina e se aprende. A respeito dos

5. Deste ponto em diante, as palavras entre aspas se referem a trechos do relato da professora que está sendo analisado. 
Da implicância à implicação: possibilidades de ocupação da posição de...

efeitos da angústia, Lacan (1962-63/2005) propõe ser ela um afeto que não engana, porque é anterior à entrada na palavra. A certeza proveniente de uma angústia está para além do circuito das palavras, pois não se pauta nos significantes, mas no corpo. Essa parece ter sido a angústia capaz de minimizar o coro das reclamações e protestos, que mais se aproximava de um discurso implicante, para mobilizar uma ação "planejada” cuidadosamente para tirar proveito pedagógico da situação, o que poderia se configurar em um discurso implicado.

Um segundo ponto concerne à posição discursiva que a professora ocupa. No lugar de se colocar na posição de Mestre e impor um saber inquestionável, a professora suspende o saber para instituir uma posição de escuta. Tal ação se dá logo na retomada das aulas, quando a professora institui um espaço para os alunos falarem de seu incômodo. Sabedora, porém, de que estava lidando com adolescentes e que, por isso, o episódio corria o risco de dar mais voz ao discurso implicante, a professora negocia regras claras para reger as interações: cada aluno deveria sintetizar, justificar, argumentar e refletir sobre seus sentimentos. Tais procedimentos instalaram a contenção ao discurso implicante, oportunizaram aos alunos a necessidade de sustentar sua palavra e dar provas do porquê de sua "eleição", encorajando uma responsabilização por aquilo que o sujeito diz. Assim fazendo, a professora parece dar mostras de estar genuinamente interessada no que os alunos têm a dizer sobre seus "sentimentos", investindo na horizontalidade das relações, ao mesmo tempo em que garante uma posição de suposto saber, capaz de manter uma certa assimetria que lhe confere uma autoridade na justa medida. Tratou-se, portanto, de responsabilizar-se pela diferença geracional e garantir a hierarquia necessária para que ela seja respeitada e uma transmissão possa se efetuar.

A escuta proporcionou uma instância em que os alunos puderam falar, mas também escutar o que a professora tinha a dizer. Dessa instância derivou-se o respeito necessário para que ela tomasse a palavra, do lugar de quem porta um saber com valor de verdade e para que uma relação transferencial pudesse operacionalizar algo de uma transmissão do saber. Isso pode ser indiciado por dois desdobramentos. $\mathrm{O}$ primeiro foi a reivindicação da professora de que sua argumentação estava referenciada em fontes procedentes, enfatizando a importância de submeter o "achismo" daquele que implica ao crivo de um conhecimento formalizado e valorado na sociedade. O segundo, a proposta da elaboração de um mapa conceitual que teve o mapa da professora como exemplo. $\mathrm{O}$ engajamento de alguns nesta atividade indicia que os alunos reconheceram o valor do que foi explicado, mesmo 
que não concordassem inteiramente com a professora. Aqueles que não fizeram os mapas foram também afetados, pois o discurso implicante deu lugar ao silêncio ou a uma atitude de resistência responsável. Logo, os efeitos do fato de a professora ter emprestado consequência ao que os alunos relatavam, sustentado a diferença geracional e se responsabilizado pela construção de outro saber são indiciados por uma produção que dá sinais do investimento subjetivo em um saber que é passível de convocar outros a dele se apropriar.

Um terceiro ponto a ser analisado remete às identificações que puderam ser instauradas durante esse processo. As ações da professora parecem ter ensejado pontos com os quais os alunos poderiam se identificar, possibilitando o engajamento em uma produção implicada com o saber. Como indícios desse movimento destaco: a sua fala, enquanto representante da classe docente em greve e de um saber diferente do midiático sobre o acontecimento em questão; e o clip de Renato Russo, que pode ter incidido como uma produção cultural mobilizadora de identificações à posição de contestação, em vez de uma aceitação inquestionável do discurso corrente.

Uma leitura dos textos dos alunos ${ }^{6}$ mostra ainda que, apesar de a maioria poder ser considerada uma produção acima da média prevista para esta faixa etária, muitos apenas oscilaram de um extremo ao outro como resultado da intervenção da professora. A produção comparece, porém, como resposta à implicação na apropriação de uma posição de mestria. Não se trata de qualquer escrita, mas de uma escrita que demandou esforço, elaboração, investimento subjetivo, ainda que fosse para demover-se da alienação ao discurso comum para aderir novamente a outro discurso e/ ou para responsabilizar-se por aquilo que estava sendo dito. A menção da professora quanto ao seu contentamento diante da mudança de posição de alguns alunos a partir de sua fala inicial como representante docente indicia essa alienação. Sua aparente denegação em relação à ciência da impossibilidade de "mobilizar todos" em favor do que colocava como as verdadeiras "causas do movimento" também comparece como um indício do desejo de transmissão ali em jogo.

Entretanto, é relevante assinalar que, apesar da configuração de uma aposta em uma ação pedagógica que conta com a subjetividade e que, portanto, já prevê a impossibilidade do todo, a professora em questão enuncia a idealização e o desejo de completude constitutivos da posição de professor. Como indícios desse modo

6. Os textos foram disponibilizados no site da escola, mas por razões éticas não puderam ser citados aqui. Porém, apesar de não comporem o objeto direto de análise deste artigo, devem ser considerados enquanto efeitos da ação analisada. 
Da implicância à implicação: possibilidades de ocupação da posição de...

de ocupação da mestria configuram-se a suposição de que o saber do professor é o saber "procedente"; a menção da professora quanto ao seu contentamento diante da mudança de posição de alguns alunos a partir de sua fala inicial como representante docente; e a aparente denegação em relação à ciência da impossibilidade de "mobilizar todos" em favor do que colocava como as verdadeiras "causas do movimento".

Apesar de considerada encerrada a intervenção, seus efeitos deram mostra de serem duradouros. Tempos depois, absorta em uma rede social, a professora foi chamada para o bate-papo por uma de suas ex-alunas, que contou haver escrito, em parceria com outra colega, uma carta para a então presidente Dilma Roussef. A aluna pedia que a professora lesse a carta e opinasse quanto a se elas deveriam ou não encaminhá-la ao destinatário. $\mathrm{O}$ resultado foi a publicação do texto no site da escola e uma matéria no principal jornal da cidade com trechos da carta enviada?

A produção inesperada dá mostras de que uma escolha pedagógica pautada na angústia resultante da falta pode suscitar uma transmissão perpassada pela transferência, indiciando os efeitos que a implicação em uma posição pode surtir. Semelhantemente, indicia efeitos de uma formação responsável, que convoca aquele colocado na posição de mestria a ousar ultrapassar os limites do tecnicamente esperado, demover-se de uma posição acomodada e implicante, desidealizar a dinâmica pedagógica e inventar modos de implicar aqueles que estão sob sua responsabilidade na construção do saber.

\section{REFERÊNCIAS}

ARENDT, H. Entre o passado e o futuro. Trad. Mauro W. Barbosa de Almeida. 5. ed. São Paulo: Perspectiva, 2005.

BAGHIN-SPINELLI, D. C. M. Ser professor (brasileiro) de língua inglesa: um estudo dos processos identitários nas práticas de ensino. 2002. 210 fls. Tese (Doutorado em Linguística Aplicada) Instituto de Estudos da Linguagem, Universidade Estadual de Campinas, Campinas, 2002.

BARZOTTO, V. H. Se acender tem que queimar: mas entre declarações e atos algo derrete na língua. In: RIOLFI, C.; BARZOTTO, V. H. (Org.). Sem choro nem vela: carta aos professores que ainda vão nascer. São Paulo: Paulistana, 2012. p. 25-34.

FOUCAULT, M. (1975). Vigiar e punir. 16. ed. Rio de Janeiro: Vozes, 1997.

JONAS, H. O princípio responsabilidade: ensaio de uma ética para a civilização tecnológica. Rio de Janeiro: Contraponto; Ed. PUC-Rio, 2006.

LACAN, J. (1969-70). O seminário livro 17. O avesso da Psicanálise. Rio de Janeiro: Jorge Zahar, 1992.

7. A carta encontra-se reproduzida no anexo. 
. (1962-63). O seminário livro 10: a angústia. Rio de Janeiro: Jorge Zahar, 2005.

LAJONQUIÈRE, L. Dos "erros" e em especial daquele de renunciar à educação. Notas sobre psicanálise e educação. Estilos da Clínica - USP, São Paulo, (II), v. 2, 2. sem., 1997.

LEBRUN, J. P. A perversão comum: viver juntos sem outro. Rio de Janeiro: Campo Matêmico, 2008. SANTOS, J. B. C. Entremeios da Análise do Discurso com a Lingüística Aplicada. In: FERNANDES, $\mathrm{C}$; . (Org.). Percursos da análise do discurso no Brasil. São Carlos: Claraluz, 2007.

STOLZMANN, M.; RICKES, S. M. Do dom de transmitir à transmissão de um dom. Revista da Associação Psicanalítica de Porto Alegre, Porto Alegre, ano IX, n. 16, p. 39-51, 1999.

ANEXO

Excelentíssima Presidenta Dilma,

Estudamos em uma escola há mais de 10 anos. Ela é considerada uma das melhores do país, mas neste momento está em greve.

Praticamente todo ano, nossa escola para por algum motivo, e por muitos anos acreditamos ser culpa dos professores, mas hoje entendemos que profissional satisfeito não entra em greve... e o problema recorrente é quase sempre o dinheiro.

A V. Ex. ${ }^{a}$. deve estar se perguntando por que mudamos de opinião e explicamos. Ano passado, nossa escola parou por falta de professores; como pode um país que quer crescer e se fazer mostrar em um cenário mundial deixar faltar professores em uma escola, por uma questão de detalhes!? Este ano entrou um aluno novo na escola e ele nos contou que a antiga escola dele ficou por mais de três meses sem professor de matemática!!

Algumas más línguas dizem que a intenção do governo é essa mesma, deixar o povo burro, uma massa sem opinião, um povo sem força.

Por favor, mude nossa opinião e a opinião de muitos com atitudes simples: melhore a educação! O Brasil cresceu o máximo que podia crescer sem uma educação de qualidade. Agora, isso precisa mudar. Temos exemplos em outros países de que a educação muda uma nação. Está na hora de mudar o Brasil.

Não desejamos que fiquemos como os EUA, que gastam mais do que o necessário e, no fim, muitas vezes, são infelizes. Nosso povo quer ser feliz, nosso povo já é feliz com tanta violência, com tanta impunidade, imagina com educação de qualidade... queremos ser mais felizes! Queremos olhar para nossos representantes e não sentirmos vergonha, queremos ir ao hospital e sermos bem atendidas, queremos ir à escola e sentirmos prazer em estudar! Está na hora de mudar! 
Da implicância à implicação: possibilidades de ocupação da posição de...

Nós queremos ser uma potência mundial tanto quanto a V. Ex.a. deseja, mas para isso acontecer, as coisas terão de mudar. Só pedimos que valorize nossos professores, porque educação de qualidade tem de ser para todos.

Mostre que além de ser a primeira Presidenta, é também a mulher que mudou o Brasil.

Esperamos que nos escute, pelo bem de uma nação.

Respeitosamente,

(as alunas assinam)

\section{SOBRE A AUTORA}

Carla Nunes Vieira Tavares é doutora em Linguística Aplicada (Universidade Estadual de Campinas) e em Ciências da Linguagem (Université de FrancheConté, França). É professora no curso de Letras - Licenciatura Inglês e Literaturas - da Universidade Federal de Uberlândia. Coordena o projeto de pesquisa "Ensino-aprendizagem de línguas: relações com o saber na contemporaneidade" e participa como pesquisadora do Grupo de Pesquisa e Estudos sobre Linguagem e Subjetividade (GELS), cadastrado no CNPq. Interessa-se pelo ensino-aprendizagem de línguas, pela formação de professores e, em especial, pelos efeitos na posição sujeito do atravessamento da subjetividade na linguagem. E-mail: carla@sonner.com.br

Recebido em 11 de novembro de 2016 e aprovado em o7 de fevereiro de 2017. 